\section{The application of liposomal azelaic acid, 4-n butyl resorcinol and retinol serum enhanced by microneedling for treatment of malar pattern melasma: A case series}

\author{
Arie Kusumawardani, \\ Anggana Rafika Paramitasari, \\ Susanti Rosmala Dewi, \\ Ance Imelda Betaubun \\ Dermatovenereology Department \\ Faculty of Medicine Sebelas Maret \\ University dr. Moewardi General \\ Hospital of Surakarta, Indonesia
}

\begin{abstract}
Melasma is a common hypermelanosis disorder that can be frustrating both for patients and physicians because it is very difficult to treat. Azelaic acid, 4-n-butylresorcinol and retinol is some of treatment modalities for melasma, but until now there is no clinical trial studies about combination of these three agents. We reported three mixed type melasma patients whom we treated using liposomal serum containing azelaic acid, 4-n-butylresorcinol and retinol combined with microneedling. We measured the improvement with modified Melasma Severity Index (MASI), Melasma Severity Scale (MSS) and Melas-QoL quesionner. At the start of the trial the average MASI score of all patients was 5.9, MSS was moderate and Melas QoL was 55.3. We re-applied treatment every 14 days for four times. There were improvements in their MASI with the ranged of $41.7 \%-85 \%$, and Melas-QoL 38.8-83.3\%. All of MSS in these three patients was classified into mild in the end of therapy.
\end{abstract}

\section{Introduction}

Melasma is a hypermelanosis on sunexposed areas in the face, ${ }^{1}$ with irregularly shaped, well defined, light to dark brown pigmentation. $^{2}$ The pathogenesis is poorly understood, but genetic and hormonal factors in combination with UV radiation play important role. ${ }^{1}$

The objectives of melasma therapy are protection from sunlight and depigmentation agent. Pigment reduction can be achieved by using chemicals that interfere with various steps of the melanogenesis pathways by retarding proliferations of melanocytes, inhibiting melanosome formation and melanin synthesis, and enhanc- ing degradation of melanosome. ${ }^{3}$

Azelaic acid (AA) is anti-proliferative and selectively cytotoxic to hyperactive melanocytes, inhibiting tyrosinase and mitochondrial oxidoreductase enzymes with minimal effects on normal pigmented skin. ${ }^{3}$ It also has an anti-inflammatory, antibacterial and anti-keratinizing effects. ${ }^{4} 4-n-$ butylresorcinol is a derivative of resorcinol that inhibits tyrosinase and tyrosinase related protein (TRP-1). ${ }^{5}$ Studies have shown good efficacy and safety with 4-n-butylresorcinol in patients with melasma., Tretinoin is widely used for the treatment of melasma as an over-the-counter lightening agent. $^{5}$ The mechanism of action is stimulating turnover of keratinocyte, decreasing melanosome transfer and allowing greater penetration of other ingredients. ${ }^{8}$

Some studies reported about the efficacy of AA, 4-n-butylresorcinol and tretinoin, either as a single or combination with other treatment modalities, but until now there is no clinical trial demonstrating the combination of these three agents. Enhancing penetration of topical products can be accomplished by using some methods, such as iontophoresis, electrophoresis, ultrasound, microneedling and nano technology. ${ }^{9}$ Microneedling devices that applied to the skin will create a controlled depth of microchannels, which close within minutes, during which time topical substances can be delivered and captured. ${ }^{10}$ Liposome encapsulation can enhance penetration and improve stabilization of the product. ${ }^{11}$ This case series aimed to investigate the efficacy of topical azelaic acid, 4-n butyl resorcinol and retinol in liposomal preparation as a therapy for melasma.

\section{Case Report}

We reported three cases of women, aged 40-45 years old, with melasma in their face. Most of them had complained about melasma since more than 3 years ago. Physical examination revealed marked hyperpigmented patches in their malar regions. We further examined their skin with simple skin stretching and wood lamp, thus we diagnosed them with mixed type malar pattern melasma.

We applied 0.5-1 $\mathrm{ml}$ serum containing azelaic acid, 4-n butyl resorcinol and retinol combined with application of $0.5-1 \mathrm{~mm}$ depth microneedling instrument. The treatment proceeded with back and forth movements, approximately 10 times in 4 directions, drawing four bands that overlapped, resulting in a diffuse erythema and discrete punctuated bleeding. All of these patients received none of topical therapy but SPF 30
Correspondence: Arie Kusumawardani. Dermatovenereology Department Faculty of Medicine Sebelas Maret University/dr. Moewardi General Hospital of Surakarta. Jl. Ir Sutami No. 36A, Jebres, Surakarta, Central Java 57126.

Tel.: 08122840012.

E-mail: arie_dr2008@yahoo.com

Key words: azelaic acid, 4-n-butylresorcinol, retinol, microneedling, melasma.

Acknowledgments: There was no conflict of interest in this study. The authors gratefully

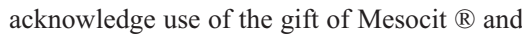
Nanopore stylus $02 \AA$ which we received from Mediderma, Spain.

Contribution: the authors contributed equally Conflict of interest: the authors declare no potential conflict of interest.

Funding sources: none.

Received for publication: 1 February 2019. Accepted for publication: 20 February 2019.

This work is licensed under a Creative Commons Attribution-NonCommercial 4.0 International License (CC BY-NC 4.0).

(C) Copyright A. Kusumawardani et al., 2019 Licensee PAGEPress, Italy

Dermatology Reports 2019; 11(s1):8075 doi:10.4081/dr.2019.8075

sunblock in the morning.

Photographic documentation was performed by the same investigator with the same digital camera immediately before the procedure and after therapy. We had 2 different examiners to measure patients' MASI and MSS scores at the beginning and the end of the therapy. The quality of life (QoL) in these three patients was also assessed using Melas-QoL questionnaire. Improvement was achieved in all patients, both in the MASI, MSS as well as MelasQoL scores (Table 1) and physical appearance (Figures 1 and 2).

\section{Discussion}

There are three typical patterns of melasma distribution, that are centro facial, malar and mandibular patterns. Centro facial pattern is the most common type, and it is involved the cheeks, forehead, upper lip, nose, and chin. The malar pattern affects nose and cheeks. The other type, mandibular pattern, are less common. ${ }^{2}$ All of the patients in this case series had malar pattern of melasma.

Pathogenesis of melasma is still poorly 


\section{Case Report}

understood, but some risk factors could be involved including various vascular growth factors, genetic, and the role of H19, inducible nitric oxide synthase (iNOS), and Wnt pathway modulator genes. ${ }^{5}$ Specific precipitators of melasma include birth-control pills, estrogen replacement therapy, mild ovarian or thyroid dysfunction, ovarian tumors, cosmetics, nutrition, phototoxic and photo allergic medications, phototoxic drugs, and medication for epilepsy. ${ }^{1}$ All of these three patients had history of taking birth-control pills containing ethynilestradiol or levonorgestrel. None of them has ever seen dermatologist to treat their melasma or taken any medication of any kind of diseases.

The treatment of melasma includes topical formulations, chemical peels, lasers, and light sources. No single therapy has proven to be of benefit to all patients as the sole therapy, so combinations therapy can be used to optimize management in difficult cases. ${ }^{8}$ This case series used microneedling to enhance penetration of selected topical solution. The depth of microneedling varied from $0.5-1.0 \mathrm{~mm}$. Open pilot trial conducted by Lima, et al. involving six women with facial refractory melasma submitted to two sessions of microneedling each 30 days followed by daily triple combination and broad-spectrum sunscreen. ${ }^{10-12}$ In their trial, there was a significant reduction of MASI score, MELASQoL and increase in L* colorimetric value. Histologically, all cases also evidenced thickening in epithelium, decreasing in melanin pigmentation and densification of upper dermis collagen. ${ }^{12}$ Microneedling will restore upper dermal and basal membrane damage in melasma by disrupting the contact of melanocytes with dermal and releasing melanogenic stimuli as endothelin, stem cell and hepatocyte growth factor. ${ }^{12}$

Azelaic acid is a saturated dicarboxylic acid to be used in the treatment of post inflammatory pigment alteration (PIPA). Although it is not fully understood, AA appears to be attributed to its ability to inhibit the energy production and/or DNA synthesis of hyperactive melanocytes, and partially to its anti tyrosinase activity. ${ }^{2}$ Balina at al study showed that AA was as effective as HQ 4\%, but without its side effects such as exogenous ochronosis. ${ }^{4}$ Faghihi et al. in their study showed that triple-combination solution of Azelaic Acid (20\%), Resorcinol (10\%) and Phytic Acid $(6 \%)$ was found to be an effective and safe peeling agent in the treatment of melasma and it was as effective as $50 \%$ glycolic acid peel. ${ }^{4}$

Kolbe et al. in their study proved the high inhibitory capacity of 4-n-butylresorci-
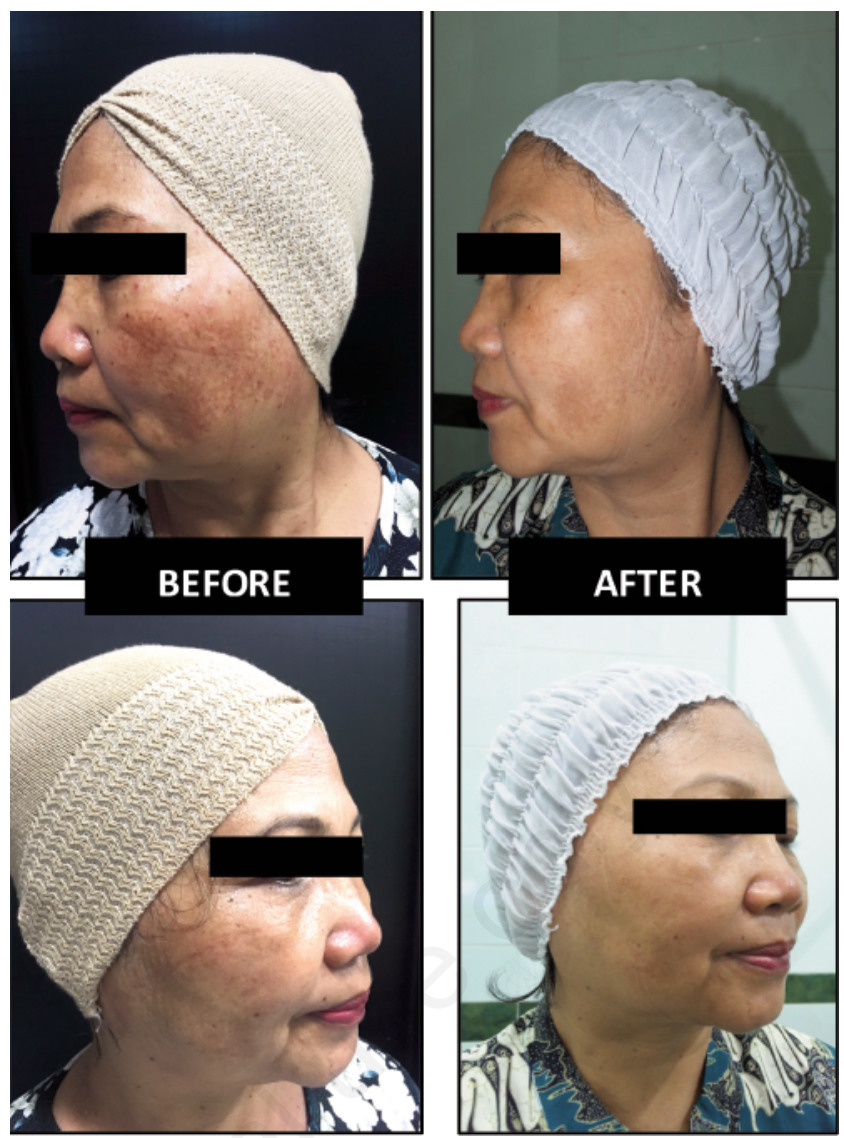

Figure 1. Patient 1.
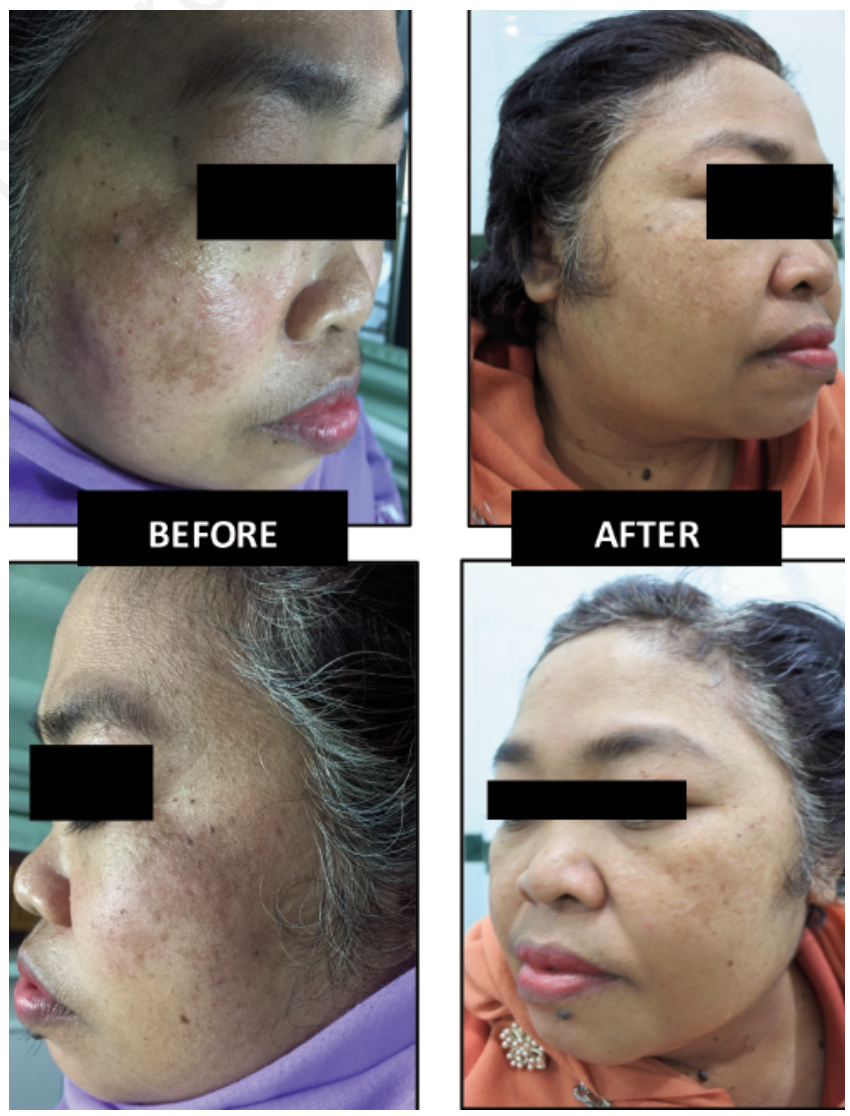

Figure 2. Patient 2. 
Table 1. Result of Modified MASI, MSS and Melas-QoL scores.

\begin{tabular}{|c|c|c|c|c|c|c|c|c|}
\hline \multirow{2}{*}{ SUBJECTS } & \multicolumn{3}{|c|}{ Modified MASI } & \multicolumn{2}{|c|}{ MSS } & \multicolumn{3}{|c|}{ MELAS-QOL } \\
\hline & B & A & $\%$ & BEFORE & AFTER & B & A & $\%$ \\
\hline Patient 1 & 6 & 0.9 & $85 \%$ & moderate & mild & 60 & 10 & $83.3 \%$ \\
\hline Patient 2 & 7.2 & 4.2 & $41.7 \%$ & moderate & mild & 57 & 17 & $70.2 \%$ \\
\hline Patient 3 & 4.5 & 3 & $33.3 \%$ & moderate & mild & 49 & 30 & $38.8 \%$ \\
\hline
\end{tabular}

*B: before, A: after.

nol on human tyrosinase activity, comparing with the potency of hydroquinone, arbutin and kojic acid. ${ }^{7}$ Huh et al. in their randomized controlled split-face trial in 23 melasma patients evaluated the efficacy and safety of liposome-encapsulated 4-n-butylresorcinol $0.1 \%$ cream. They found a statistical significant reduction $(\mathrm{P}<0.043)$ in the melanin index on the treatment side. ${ }^{6}$

Faghihi et al. performed a randomized, double-blinded clinical trial to compare the efficacy of $1 \%$ tretinoin peel versus $70 \%$ GA peel in 63 female patients with bilateral melasma. It was found that the efficacy of $1 \%$ tretinoin peel was similar to $70 \%$ GA. Postprocedure discomfort as expressed by the patients was significantly lower with $1 \%$ tretinoin. $^{13}$

We used liposomal serum containing combination of azelaic acid, 4-n-butylresorcinol and retinol. The activity of liposomal formulations in skin care cosmetics is attributed to its occlusive action and it may also have other benefits in cosmeceutical products, such as improving drug stability, in modulating drug release, as targeting agents, enhanced bioavailability, reduction of systemic absorption, and reduction of side effects. ${ }^{11}$ The Melasma Area and Severity Index was developed by Kimbrough-Green, et al. to provide a more accurate quantification of the severity of melasma and changes during therapy. ${ }^{14}$ However, Pandya, et al. proposed modified MASI and recommended removal of homogeneity from the MASI score because it is easy to learn and perform. ${ }^{14}$ Another measurement that can be used for melasma is MSS. ${ }^{14}$ In 2003 Balkrishnan, et al. developed and validated the Melas-QoL to asses quality of life in melasma patients. ${ }^{15}$ In our case series we used modified MASI, MSS and Melas-QoL to measure improvement in our patients. MASI, MSS and Melas-QoL improved in all of our patients with the scores of $33.3 \%-85 \%$, moderate-mild, and $38.8-83.3 \%$ respectively.

\section{Conclusions}

The combination of modalities therapy is needed to optimize the management of melasma. As it is revealed in the result of our case series, liposomal formula of azelaic acid, 4-n-butylresorcinol and retinol had been proven to lower modified MASI, MSS and Melas-QoL scoring in melasma patient. Application of this formula can be enhanced by microneedling. Further studies with larger population can be done in order to get a better statistical significance.

\section{References}

1. Lapeere H, Boone B, Schepper S D, Verhaeghe E, Van Gele M, Ongenae K, Van Geel N, Lambert J, Brochez L. Hypomelanoses and hypermelanoses. dalam: Lowell A. Goldsmith SIK BAG, Amy S. Paller, David J. Leffell, Wolf K, editor. Fitzpatrick's dermatology in general medicine. 1. New York: Mc Graw-Hill; 2012. hal. 804-26.

2. Baumann L, Saghari S. Skin pigmentation and pigmentation disorder. dalam: Bauman L, Saghari S, Weisberg E, editor. Cosmetic dermatology principles and therapy. 1. 2 ed. New York: Mc Graw Hill; 2009. hal. 98-108.

3. Shankar K, Godse K, Aurangabadkar S, Lahiri K, Mysore V, Ganjoo A, dkk. Evidence-based treatment for melasma: Expert opinion and a review. Dermatol Ther (Heidelb). 2014;4(2):165-86.

4. Faghihi G, Taheri A, Shahmoradi Z, Nilforoushzadeh M A. Solution of azelaic acid $(20 \%)$, resorcinol $(10 \%)$ and phytic acid $(6 \%)$ versus glycolic acid $(50 \%)$ peeling agent in the treatment of female patients with facial melasma. Adv Biomed Res. 2017;6:9.

5. Sarkar R, Arora P, Garg V K, Sonthalia S, Gokhale N. Melasma update. Indian Dermatol Online J. 2014;5(4):426-35.

6. Huh S Y, Shin J W, Na J I, Huh C H, Youn S W, Park K C. Efficacy and safety of liposome-encapsulated 4-n-butylresorcinol $0.1 \%$ cream for the treatment of melasma: A randomized controlled split-face trial. J Dermatol. 2010;37(4): 311-5.

7. Kolbe L, Mann T, Gerwat W, Batzer J, Ahlheit S, Scherner C, dkk. 4-n-butylresorcinol, a highly effective tyrosinase inhibitor for the topical treatment of hyperpigmentation. J Eur Acad Dermatol Venereol. 2013;27 Suppl 1:19-23.

8. Sheth V M, Pandya A G. Melasma: A comprehensive update: Part ii. J Am Acad Dermatol. 2011;65(4):699-714; quiz 5.

9. Escobar-Chávez J J, Rodríguez-Cruz I M, Domínguez-Delgado C L. Chemical and physical enhancers for transdermal drug delivery. 2012. dalam: Pharmacology [Internet]. Mexico: InTech; [397-435]. Available from: http://www.intechopen.com/books/phar macology/chemical-andphysicalenhancers-for-transdermal-drugdelivery.

10. Lee J C, Daniels M A, Roth M Z. Mesotherapy, microneedling, and chemical peels. Clin Plast Surg. 2016;43(3):583-95.

11. Soni V, Chandel S, Jain P, Asati S. Role of liposomal drug-delivery system in cosmetics. dalam: Grumezescu AM, editor. Nanobiomaterials in galenic formulations and cosmetics applications of nanobiomaterials. Oxford: Elsevier; 2016. hal. 93-120.

12. Lima E V A, Lima M, Paixao M P, Miot H A. Assessment of the effects of skin microneedling as adjuvant therapy for facial melasma: A pilot study. BMC Dermatol. 2017;17(1):14.

13. Faghihi G, Shahingohar A, Siadat A H. Comparison between $1 \%$ tretinoin peeling versus $70 \%$ glycolic acid peeling in the treatment of female patients with melasma. J Drugs Dermatol. 2011;10(12):1439-42.

14. Pandya A G, Hynan L S, Bhore R, Riley F C, Guevara I L, Grimes P, dkk. Reliability assessment and validation of the melasma area and severity index (masi) and a new modified masi scoring method. J Am Acad Dermatol. 2011;64(1):78-83, e1-2.

15. Handel A C, Miot L D, Miot H A. Melasma: A clinical and epidemiological review. An Bras Dermatol. 2014;89(5):771-82. 